\title{
Mathematical simulation of thermal state of digital current and voltage transformer in unfavourable weather conditions
}

\author{
Elena E. Gotovkina ${ }^{1}$, Grigory I. Parfenov ${ }^{1}$, Nikolay N. Smirnov ${ }^{1, *}$, Vladimir D. Lebedev ${ }^{1}$, \\ and Vladimir $\mathrm{V}$. Tyutikov ${ }^{1}$ \\ ${ }^{1}$ Ivanovo State Power Engineering University, 153003 Ivanovo, Russia
}

\begin{abstract}
This study examines issues relating to heat exchange between an innovative $6(10) \mathrm{kV}$ current and voltage transformer (and its components) and its environment in unfavourable weather conditions. Existing designs of digital current and voltage transformers are featured in systems of commercial and technical electric power accounting, and also relay protection and automation. We have presented the results of mathematical simulation of the thermal state of both a single resistor included in our measuring device, and the digital transformer as a whole. Simulation was performed using the finite element method. We have taken into account the impact of such factors as direct and diffused solar radiation, high ambient temperatures and various voltage levels on the thermal state of the functioning equipment. To verify the developed mathematical model we have presented the results of a series of experiments conducted in a high-voltage environmental chamber. Our study conclusively shows that voltage, insolation and ambient temperature significantly affect the thermal state of a functioning current and voltage transformer.
\end{abstract}

\section{Introduction}

The digital instrument transformer [1] consists of a resistive voltage divider and current transformer (see Figure 1). Several resistors are contained within the body of the voltage instrument transformer.

The electrical processes occurring in resistive voltage dividers comprising a group of resistors entail heat emission. Overheating of a resistor may result in failure of the measuring equipment under review.

Methods of thermal protection against overheating of power transformers are widely known [2]. Unfortunately, thermal tests during operation of power transformers, and even more so in the case of current and voltage instrument transformers (especially new types) are often performed according to maintenance schedules [3], which negatively impacts the reliability of such electrical equipment [4]. Developing new systems of self-diagnostics checks for the thermal state of digital instrument transformers that determine temperature

* Corresponding author: nsmirnov@bk.ru 
according to the most heated up electrical equipment part in real time is therefore an important task, especially in the development of "smart" power grids.

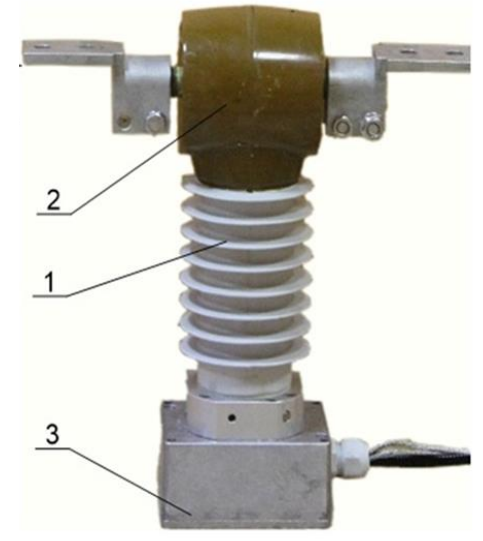

Fig. 1. External view of a $6(10) \mathrm{kW}$ digital combined transformer: 1 - primary voltage converter; 2 - primary current power converter; 3 - low voltage electronic unit.

Instrument transformers may be located either inside electric power substations or in the open air [1]. If in the former case a mechanical ventilation system to cool the transformer may be provided, it is impossible to control ambient air parameters in the open air. Instrument transformer operation in no-wind conditions (natural convection), high ambient temperatures and insolation, or in emergency mode (for example, with intermittent arcing faults) is the least favourable option from the point of view of heat exchange.

An indispensable stage of research in developing algorithms for transformer selfdiagnostics is mathematical simulation of transformer thermal state under the above unfavourable weather conditions. Among the well known methods of solving differential equations that describe heat exchange, including methods of finite differences and algorithms for their implementation [5,6], we chose the finite elements method [7], which has demonstrated highly accurate results in the simulation of complex heat exchange. The mathematical model was realized using COMSOL Multiphysics.

\section{Description of mathematical model of heat exchange between a transformer (and resistor) with its environment}

Mathematical simulation of heat exchange was performed both for the entire digital current and voltage transformer and for the cylindrical measuring resistor with $R_{l}$ resistance, placed in insulation material identical to the one used in the transformer.

A diagram of the mathematical model of heat exchange between a transformer and its environment in conditions of natural convection is shown in Figure 2. The model included description of thermal conductivity inside the transformer, heat transfer from its surface, heat emissions from heating elements, and also diffused and direct solar radiation.

Since the transformer is intended to operate in the open air and exposed to insolation (see Figure 2), with surface temperatures $t_{\text {surf }}$ exceeding ambient temperature $t_{a m b}$, the thermal balance for this model may be written as follows:

$$
Q_{e l}+Q_{i n s}^{d i r}+Q_{i n s}^{d i f f}=Q_{c o n v}+Q_{\text {rad }},
$$

where $Q_{e l}$ - heat, released according to the Joule-Lenz law during passage of electric current through the conducting parts of a combined transformer, $\mathrm{W} ; Q_{i n s}^{d i r}-$ heat from direct 
solar radiation, W; $Q_{i n s}^{\text {diff }}$ - heat from diffused solar radiation, W; $Q_{\text {conv }}$ - convection heat flow from heated transformer surface to ambient air, W; $Q_{\text {rad }}$ - radiation heat flow from heated transformer surface to surrounding objects, $\mathrm{W}$.

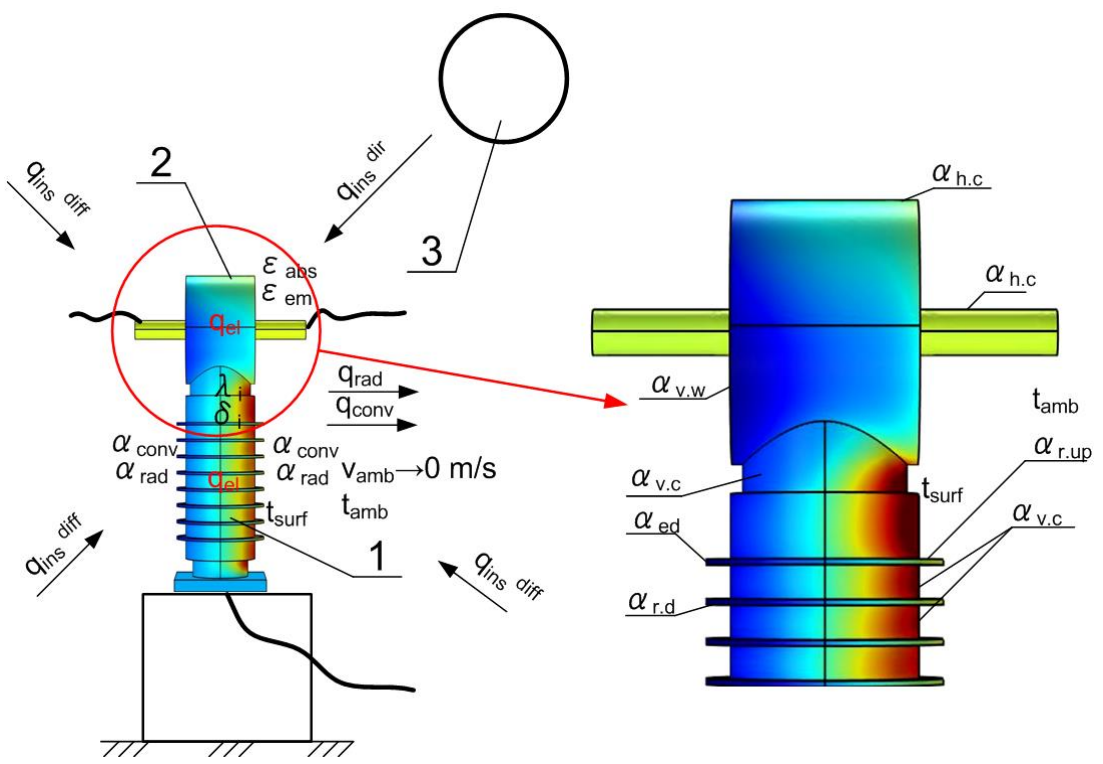

Fig. 2. Diagram of the mathematical model of heat exchange between a combined transformer and its environment: 1 - primary voltage converter; 2 - primary current power converter; 3 - Sun.

When electric current passes through the transformer with voltage supply, heat energy $q_{e l}, \mathrm{~W}$, is released in the primary current and voltage converters according to the Joule-Lenz law. Solid state insulation, comprising layers of material of thickness $\delta$ and heat conductivity coefficient $\lambda$, creates additional resistance to removal of heat from the resistors. The physical heat properties of the solid materials were set with the aid of constants [8].

Ambient air is the operating environment, receiving heat emissions form electrical equipment. Heat transfer from the heated surface of a transformer to its environment is due to radiation $q_{\text {rad }}$ and convection $q_{c o n v}$. Convection heat transfer is characterized by heat flux density $q_{\text {conv }}, \mathrm{W} / \mathrm{m}^{2}$, and heat transfer coefficient $\alpha_{c o n v}, \mathrm{~W} /\left(\mathrm{m}^{2} \cdot{ }^{\circ} \mathrm{C}\right)$.

Functions for determining Nusselt $(\mathrm{N} u)$, Grashoff $(\mathrm{Gr})$, Prandtl $(\mathrm{Pr})$, Raleigh $(\mathrm{Ra})$ criteria, dependences for calculating convection heat transfer coefficients, volumetric expansion coefficients etc. for the corresponding surfaces and instances of heat exchange were described on the basis of heat exchange theories $[8,9]$, taking into account the work of Academician M.A. Mikheyev [8] and other researchers [10], and also using data from the authors' physical experiments.

Thus, for example, after converting our values into the formula for determining the heat transfer coefficient in the vertical cylinder, we obtained:

$$
\alpha_{v, c}=\frac{0.54 \cdot\left(\frac{g \cdot R_{0}^{3}}{v^{2}} \cdot \frac{1}{T_{0}} \cdot\left|t_{\text {surf }}-t_{\text {amb }}\right| \cdot P r\right)^{0.25} \cdot \lambda_{f}}{R_{0}},
$$


where $g$ - free fall acceleration, $g=9.81 \mathrm{~m} / \mathrm{s}^{2} ; R_{0}$ - determining size (cylinder height), $v$ - kinematic air viscosity, $\mathrm{m}^{2} / \mathrm{s} ; \Delta T=\left|t_{\text {surf }}-t_{\text {amb }}\right|$ - temperature difference module between wall and ambient air, ${ }^{\circ} \mathrm{C}(\mathrm{K}) ; \lambda_{f}-$ air thermal conductivity, $\mathrm{W} /(\mathrm{m} \cdot \mathrm{K}) ; T_{0}$ - determining temperature, $\mathrm{K}$.

Coefficients of radiation heat transfer from the surface of the digital transformer to its environment $\alpha_{\text {rad }}$ were set according to the Stefan-Boltzmann formula [8], using the procedure incorporated in our software. Heat supply from direct $q_{\text {ins }}^{\text {dir }}$ and diffused $q_{\text {ins }}^{\text {diff }}$ solar radiation was set by means of a function. The quantity of obtained solar energy also depends on coefficients of absorption $\varepsilon_{a b s}$ and emission $\varepsilon_{e m}$ of the materials used in making the transformer outer casing.

This study is also interesting because account is taken of heat emissions from working equipment in both voltage and current transformers in our combined measuring device, and their total impact on the thermal state of the combined digital transformer during a certain time. Heat emissions from precision resistors in the voltage transformer were calculated according to the Joule-Lenz law and set with the aid of a function depending on electric grid mode, simulating various values of voltage and current.

Thermo-physical properties of ambient air were described with the aid of a function, based on reference literature [8].

\section{Results of mathematical simulation of heat exchange between a resistors placed in electrical insulation material and its environment}

The resistor (Figure 3, item 3) was placed in electrical insulation sheathing (Figure 3, item 4) with thermal conductivity $\lambda$.

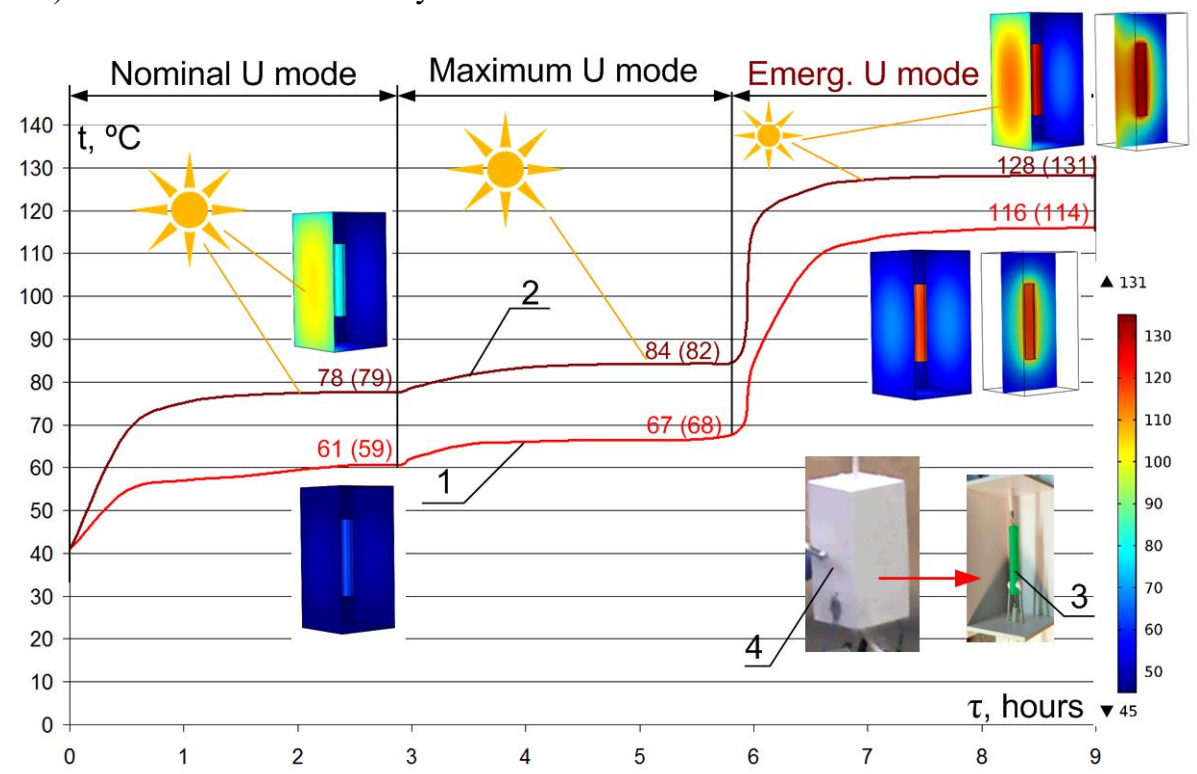

Fig. 3. Dependence of temperature on the lower cap of a resistor (3) placed in insulation material (4) on voltage and insolation: 1,2 - in the absence and under the impact of insolation on the insulation surface, respectively. 
We simulated step changes in the values of phase voltage supplied to the resistor in the following modes: nominal $U_{\text {nom.ph }}=1.92 \mathrm{kV}$, maximum $U_{\text {max.ph }}=1.2 \cdot U_{\text {nom.ph }}=2.31 \mathrm{kV}$, and emergency $U_{\text {emerg.ph }}=2.1 \cdot U_{\text {nom.ph }}=4.04 \mathrm{kV}$. Ambient temperature was set at $40{ }^{\circ} \mathrm{C}$.

Figure 3 shows the results of our simulation (for resistor temperatures obtained during a physical experiment in a high-voltage environmental chamber being given in brackets). We should note that the difference between the results of physical and computer simulation is $1-3{ }^{\circ} \mathrm{C}$, which reflects the accuracy of data obtained from simulation using COMSOL software.

In the absence of insolation with nominal voltage $U_{\text {nom.ph, }}$ resistor temperature rose to $t_{r}=61{ }^{\circ} \mathrm{C}$ in 3 hours; with voltage increased to the maximum value, the temperature rose to $67^{\circ} \mathrm{C}$ (an increase of $6^{\circ} \mathrm{C}$ ). Changing over to emergency mode resulted in the temperature rising to $116^{\circ} \mathrm{C}$ (an increase of $49{ }^{\circ} \mathrm{C}$ ). Insolation significantly increased warming of both insulation material and the resistor. Thus, with nominal voltage, resistor temperature increased by a further $17^{\circ} \mathrm{C}$ (up to $78^{\circ} \mathrm{C}$ ), with maximum voltage - by $17^{\circ} \mathrm{C}$ (up to $84^{\circ} \mathrm{C}$ ), with emergency mode - by a further $12^{\circ} \mathrm{C}$ (up to $128^{\circ} \mathrm{C}$ ).

\section{Results of mathematical simulation of heat exchange between a digital transformer and its environment}

Studies (see Figure 4) were performed for a combined digital 6(10) kV transformer (taking boundary alignment of measuring resistor parts [1]). We should note that simulation was envisaged on two kinds of mesh: large, with around 22 thousand elements, and small 39 thousand elements. The calculation process on the large mesh took about 16 minutes, on the small mesh it took 7 times longer, or around 2 hours. Errors occurred during simulation on the large mesh due to the finite element not matching some of the transformer rib dimensions. The temperature difference was $0.5-4{ }^{\circ} \mathrm{C}$.

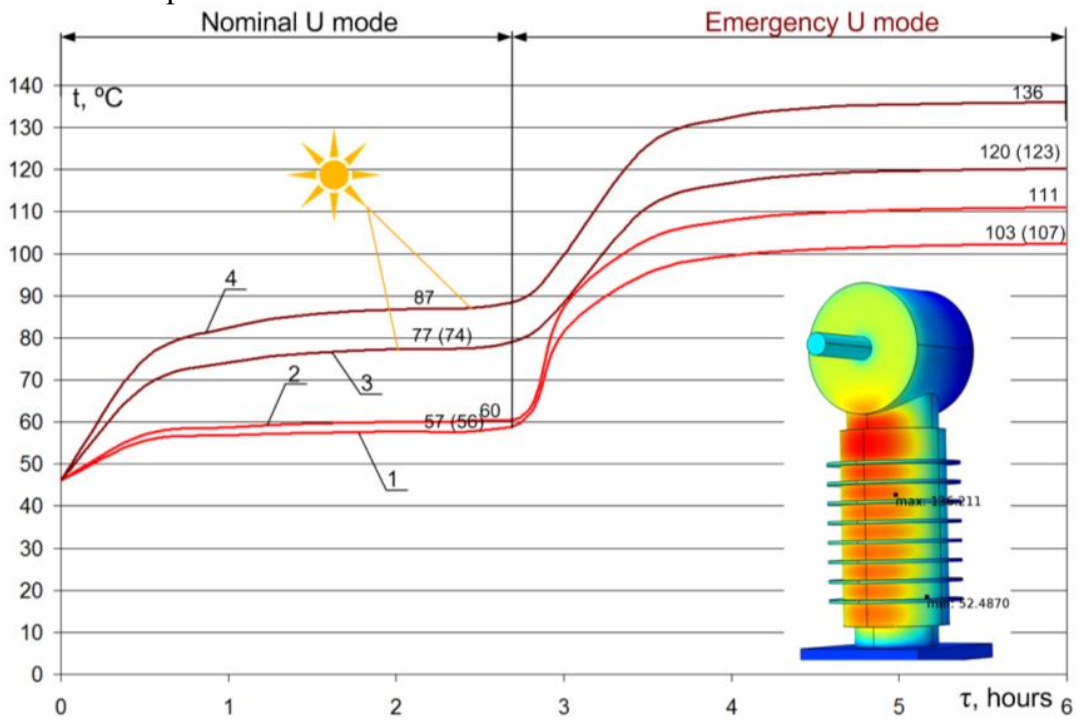

Fig. 4. Charts showing changing resistor temperature over time in nominal and emergency voltage modes: 1, 2 - temperatures at the lower and most heated resistor, respectively, without insolation; $3,4-$ the same, with insolation.

Two modes of phase voltage were set: nominal and emergency. Simulation was performed both with and without insolation on the transformer surface. The results may be seen in Figure 4, temperatures obtained during physical experiment in an environmental 
chamber being given in brackets. In the interests of electrical safety during physical experiment, temperatures were measured only on the lower caps of the lower resistors, the ambient temperature being $40{ }^{\circ} \mathrm{C}$.

From the results of our simulation, we may conclude that the difference between temperatures obtained during physical experiment and mathematical simulation did not exceed 4 degrees, which may be related to inaccurate information regarding the physical properties of the materials used. With these allowances, however, the mathematical model under review may be regarded as accurate.

A significant rise in temperature occurred when voltage was increased from nominal to emergency values. Thus, the temperature of the most heated resistor rose from 60 to $111^{\circ} \mathrm{C}$, while with insolation the temperature of the same resistor increased from 87 to $136{ }^{\circ} \mathrm{C}$. The difference between the lower and most heated resistors ranged from 3 (nominal mode, without insolation) to $16{ }^{\circ} \mathrm{C}$ (emergency mode, with insolation), which is related to the cumulative capability of the adjacent resistors and their mutual warming.

\section{Conclusion}

The developed models of heat exchange between both a resistor and a digital transformer with its environment may be regarded as adequate. These models may be used in the further development of systems of self-diagnostics for the thermal condition of a transformer. Voltage, insolation and ambient temperature significantly influence the thermal condition of a voltage and current transformer.

This research was conducted with financial support from the Ministry of Education and Science of the Russian Federation at Ivanovo State Power Engineering University within the framework of a federal target programme, "Research and Development in Priority Areas of Developing the Russian Scientific and Technological Complex in 2014-2020" concerning "A Multifunctional System based on Digital Current and Voltage Transformers for a Digital Substation" (Agreement No. 14.577.21.0276 on Granting Subsidies, dated 26 September 2017, Unique Identifier for Applied Scientific Research (Projects) RFMEFI57717X0276).

\section{References}

1. A.A. Yablokov, N.N. Smirnov, V.V. Tyutikov, V.A. Gorbunov, MATEC Web Conf. 141 (2017)

2. R. Hunt, M.L. Giordano, Thermal overload protection of power transformers operating theory and practical experience (Georgia Tech, Atlanta, 2005)

3. Z. Liang-dong, S. Hui, Power System Protection and Control 04 (2010)

4. Ju.P. Aksenov, A.V. Golubev, V.I. Zavidey, Elektro 1 (2006)

5. O.V. Vysokomornaya, G.V. Kuznetsov, P.A. Strizhak, Rus. J. Phys. Ch. B 5 (2011)

6. V.L. Strakhov, A.N. Garashchenko, G.V. Kuznetsov, V.P. Rudzinskii, Comb. Exp. Sh. W. 37 (2001)

7. G.V. Kuznetsov, V.I. Maksimov, M.A. Sheremet, J. Appl. Mech. Tech. Phys. 54, 4 (2013)

8. V.V. Buhmirov, Heat and mass transfer (ISPEU, Ivanovo, 2014)

9. M.A. Ulchiekov, E.E. Bulba, MATEC Web Conf. 92 (2017)

10. O.G. Martynenko, Yu.A. Sokovishin, Free-convective heat transfer (Nauka i technika, Minsk, 1982) 